\title{
"A la sombra del sol" y la penumbra de los tiempos de la historia ${ }^{1}$
}

Francisco Gallardo I. ${ }^{2}$

\section{RESUMEN}

El film "A la sombra del sol”, de Silvio Caiozzi y Pablo Perelman, fue estrenado en 1974 y trata de un hecho de sangre en apariencia ocurrido a finales de los cuarenta en la localidad de Caspana. Entre los efectos de realidad más poderosos del film, se cuenta con la participación de la población local como intérpretes. Un recurso propio del cine neorrealista italiano, en asociación a una imagen de carácter inequívocamente documental, permitió a los realizadores hacer ingresar el relato en el reino de la Historia como un acontecimiento real. Sin embargo, en los intersticios del film quedó registrado el gesto visual de un modo expresivo y cultural que había llegado a su fin. Positivada en la imagen de los nativos atacameños, habita la huella visible de ese "hombre nuevo" que pocos meses antes del estreno era el horizonte de la utopía de una revolución socialista.

Palabras claves: antropología - cine - marxismo - atacameños.

\section{ABSTRACT}

The film A la sombra del sol, of Silvio Caiozzi and Pablo Perelman, screening in 1974, is about a crime that happened at the end of the 40s in Caspana, a village in Northern Chile. Among the most powerful reality effects of the film, is the participation of the local population. Such an effect - a resource of Italian neorealist cinema- in association with an image characteristic of the documentary genre let the film crew make the script appear as a real event in History. In the interstices of the film, however, a visual and cultural mode of expression that had already arrived to its end was recorded. In the moving image of the native atacameños inhabits the visible print of that "new man" that a few months before the film's screening conveyed the utopia of a socialist revolution.

Key words: anthropology - cinema - marxism - atacameños.

Recibido: agosto 2005. Aceptado: noviembre 2006

1 Proyecto FONDECYT 1030029: "La ventana indiscreta: Los pueblos originarios en el cine ficción y documental chileno bajo la mirada de una antropología visual".

2 Museo Chileno de Arte Precolombino, Bandera 361, Santiago, CHILE. Email: fgallardo@museoprecolombino.cl

\section{Introducción}

A la sombra del sol, de Silvio Caiozzi y Pablo Perelman, se estrenó en el cine Las Condes de Santiago (Chile), la noche del 28 de noviembre de 1974. Fue el primer largometraje nacional realizado durante la dictadura militar. A poco más de un año del golpe de Estado, Chile vivía a la sombra del terror. Para un sector de la población, la atmósfera estaba contaminada por el miedo, una sensación de peligro instaurada como signo de una catástrofe en desarrollo. En la mañana del día siguiente al estreno del film, dos miembros del equipo realizador, la continuista, Carmen Bueno (24 años) y su pareja, el camarógrafo Jorge Müller (27 años), eran detenidos por los servicios de seguridad del régimen, para luego ser trasladados a Villa Grimaldi, un centro de tortura, y luego a Cuatro Alamos, un campo de prisioneros. Días más tarde ambos engrosaron la lista de detenidos desaparecidos. Hasta hoy, nada se sabe de ellos. A la sombra del sol se inscribió en la historia del cine chileno bajo el signo de una doble tragedia política, el colapso de la "vía chilena al socialismo" y la pérdida de sus colaboradores. Esta marca indeleble introducida por la historia política no sólo se inscribió en las vidas de estos artistas y el devenir de su obra, pues en los intersticios del film (como obra visual) también quedó registrado el gesto de un modo expresivo y cultural que había llegado a su fin. Positivada en la imagen de la cinta habita la huella visible de ese "hombre nuevo" reverenciado como esperanza y salvación de toda injusticia, anhelo que pocos meses antes era el horizonte de la utopía de una revolución socialista, cuyos protagonistas daban por hecho, negándose a imaginar el desastre.

En el presente artículo se considera al cine como un objeto de análisis cultural privilegiado, pues en tanto es un acto de comunicación de masas, un convenio tácito entre realizadores y público, debe necesariamente aludir a aquellas normas y valores -la mayoría de las veces inconscientes- que sirven en un momento dado como referentes para la acción, 
prácticas que pueden responder a estilos de vida dominantes, emergentes o residuales, pero cuyos contenidos están enteramente determinados por los contextos históricos de su aparición (Williams 1980). El cine como otras artes visuales tiene la propiedad de transformar en imágenes, de objetivar visualmente creencias cuya naturaleza puede ser puramente imaginaria. Y este es el caso de $A$ la sombra del sol, film que materializó inconscientemente las expectativas de justicia de un período social anterior a su realización.

\section{Arte y marxismo}

Arte, socialismo y revolución nos remiten con pocas dudas a la obra de Marx y Engels, a pesar de que estos nunca se manifestaron de manera sistemática respecto a las prácticas artísticas (p.e., Marx 1970 [1859]). Fue Plejanov (1929[1912]), el teórico y político que introdujo el marxismo en Rusia, quien en 1912 produjo una obra de carácter marxista donde intentaba sistematizar las relaciones del arte y la vida social. En ella, Plejanov discute la doctrina del arte por el arte, concluyendo que es resultado del "extremado individualismo de la época de decadencia burguesa" (1929 [1912]): 123). Plejanov, al igual que Franz Mehring, uno de los fundadores del Partido Comunista Alemán -que también mostró interés por el tema-, creían firmemente que el advenimiento de un arte nuevo sólo se produciría con la instauración del socialismo, dejando de manifiesto ese materialismo vulgar característico de principios del siglo XX y que nunca fue totalmente superado (Demetz 1968). Sin embargo, el arte dejó de ser mera teoría o crítica en el contexto de la revolución rusa, y son los escritos de Lenin los que declaran más abiertamente las directrices políticas del arte revolucionario, que en esa época era reducido a la literatura, el medio privilegiado de circulación masiva de las ideas:

"La literatura debe ser una parte de la causa proletaria, debe ser 'rueda y tornillo' de un solo gran mecanismo social-demócrata, puesto en movimiento por toda la vanguardia consciente de toda la clase obrera" (Lenin 1976 [1905]: 19).

El dictamen leninista es categórico, pues toda práctica en el contexto soviético emergente debía ser una práctica revolucionaria, una acción mancomunada orientada a un único fin, la propaganda. El cine ruso es un ejemplo especialmente bueno, pues luego que Lenin nacionalizara la industria cinematográfica esta fue una pieza clave en el surgimiento de obras que no sólo transformaron el campo del montaje (p.e., La huelga de Eisenstein o La madre de Pudovkin), sino también en la difusión de las ideas revolucionarias (Bilbatua 1971). Las limitaciones respecto a un arte contemplativo o indiferente a la vida social son obvias, pero es igualmente obvio que en tanto la definición es instrumental y no referida a la forma o al contenido, la creatividad podía de este modo conservar ese espacio necesario para la novedad. No fue hasta la muerte de Lenin y el advenimiento del estalinismo que el arte se volvió un campo para el ejercicio de la dominación, control exacerbado orientado a modelar la forma y el contenido cuyo propósito era simplemente el elogio gratuito del Estado, sus dirigentes y sus programas. El realismo socialista o "naturalismo burocrático" (como lo llamaba Lukács 1969[1963]) suplantó al ser del sujeto en beneficio del ser del Estado, una fórmula que fuera de la órbita soviética pocos creyeron legítimo aceptar.

\section{Artistas chilenos y posiciones revolucionarias}

Las tradiciones del pensamiento marxista y leninista, las experiencias revolucionarias de distintas épocas de la historia mundial y la propia historia revolucionaria de los trabajadores y campesinos chilenos fueron el sustento del programa y gobierno de la Unidad Popular. Artistas de las más distintas especialidades se sumaron a "La vía chilena al socialismo", y fueron ellos quienes hicieron relevante el tema del arte y la vida social, de la creación y la construcción del socialismo, problemas que ellos habían explorado con entusiasmo desde la década de los 60. Hubo consenso en la importancia de los valores populares como fuente de reflexión cultural, y los artistas contribuyeron activamente en la transformación del arte en instrumento de acción política. Sin embargo, los modos expresivos no pueden ser descritos exclusivamente como realismo socialista o propaganda, sino más bien como un espacio polifacético de experimentación con raigambres tan distintas como el pop europeo y norteamericano, la fotografía social de principios de siglo, el muralismo mexicano o el folklore latinoamericano. Una apertura heterogénea en la que también coexistieron el rock and roll, el surrealismo de Matta y la poesía de Neruda.

En el cine, la preocupación por lo social se inició temprano (Mouesca y Orellana 1998). A finales de los años 50, el film Tres miradas a la calle (1957) de Naum Kramarenko fue considerado por los críticos 
como una obra neorrealista, un influyente movimiento de cine social de la Italia de postguerra. Sin embargo, existe poca duda de que Largo viaje (1967) de Patricio Kaulen es la película más abiertamente neorrealista en la historia del cine chileno. Obra que junto a Tres tristes tigres de Raúl Ruiz, El Chacal de Nahueltoro de Miguel Littin (1969), Valparaíso, mi amor de Aldo Francia (1969) y Caliche sangriento de Helvio Soto (1969) marcaron el rumbo del Nuevo Cine Chileno de los 60.

Este desplazamiento de la ficción a la realidad entre los realizadores chilenos quedó de manifiesto en el notorio crecimiento del género documental, cuyo número en la década de los 60 fue superior al género de ficción. Sergio Bravo, Jorge di Lauro, Nieves Yankovich, Patricio Guzmán y Pedro Chaskel son las figuras emblemáticas de este género en los años previos a la Unidad Popular. Las influencias más claras en estas producciones fueron el documentalismo social europeo y el cinema verité. En el año 1962, Joris Ivens -un documentalista social de larga trayectoria- visita Chile y filma el documental Valparaíso. Comienza la primavera, que es rechazado por la censura. Ese mismo año el sociólogo francés Edgar Morin realiza el documental Alameda -con la colaboración de Patricio Guzmán y Pedro Chaskel- y exhibe en la Biblioteca Nacional Crónica de un verano, obra realizada junto a Jean Rouch, uno de los fundadores del cine etnográfico (Mouesca y Orellana 1998: 266-270).

Durante el gobierno de Salvador Allende, y al igual que otros artistas, los cineastas sintieron la necesidad de establecer un compromiso propio conforme a las necesidades del proceso político (Vega 1980). En 1970, Miguel Littin, entonces director de Chile Films, suscribe, junto a Helvio Soto, Sergio Bravo, Aldo Francia, Patricio Guzmán y otros realizadores, el Manifiesto de los cineastas de la Unidad Popular, donde entre otras declaraciones de principios se proclama:

"1. Que antes que cineastas somos hombres comprometidos con el fenómeno político y social de nuestro pueblo y con su gran tarea: la construcción del socialismo.

2. Que el cine es un arte.

3. Que el cine chileno, por imperativo histórico, deberá ser un arte revolucionario.

4. Que entendemos por arte revolucionario aquel que nace de la realización conjunta del artista y del pueblo unidos por un objetivo común: la liberación. Uno, el pueblo, como motivador de la acción y en definitiva el creador, y el otro, el cineasta, como su instrumento de comunicación.

5. Que el cine revolucionario no se impone por decreto. Por lo tanto no postulamos una forma de hacer cine sino de tantas como sean necesarias en el transcurrir de la lucha.

(...)

10. Que no existen films revolucionarios en sí. Que estos adquieren categoría de tales en el contacto de la obra con su público y principalmente en su repercusión como agente activador de una acción revolucionaria.

11. Que el cine es un derecho del pueblo y como tal deberán buscarse las formas apropiadas para que este llegue a todos los chilenos.

12. Que los medios de producción deberán estar al alcance por igual de todos los trabajadores del cine y que en este sentido no existen derechos adquiridos, sino que por el contrario, en el gobierno popular, la expresión no será un privilegio de pocos sino el derecho irrenunciable de un pueblo que ha emprendido el camino de su definitiva independencia.

13. Que un pueblo que tiene cultura es un pueblo que lucha, resiste y se libera.

\section{CINEASTAS CHILENOS, VENCEREMOS" (Vega 1980: 43-44). ${ }^{3}$}

No sabemos qué tan influyente pudo ser este manifiesto entre los cineasta, pero lo cierto es que fue

\footnotetext{
El Manifiesto incluye también: "6. Que no obstante pensamos que un cine alejado de las grandes masas se convierte fatalmente en un producto de consumo de la élite pequeño-burguesa que es incapaz de ser el motor de la historia. El cineasta, en este caso, verá su obra políticamente anulada.

7. Que rechazamos todo sectarismo en cuanto a la aplicación mecánica de los principios, o a la imposición de criterios formales oficiales en el quehacer cinematográfico.

8. Que sostenemos que las formas de producción tradicionales son un muro de contención para los jóvenes cineastas y en definitiva implican una clara dependencia cultural ya que dichas técnicas provienen de estéticas extrañas a la idiosincrasia de nuestros pueblos. A una técnica sin sentido oponemos la voluntad de búsqueda de un lenguaje propio que nace de la inmersión del cineasta en la lucha de clases, enfrentamiento que genera formas culturales propias.

9. Que sostenemos que un cine con estos objetivos implica necesariamente una evaluación crítica distinta, afirmamos que el gran crítico de un film revolucionario es el pueblo al que va dirigido, quien no necesita mediadores que lo defiendan y lo interpreten" (Vega 1980: 43-44).
} 
suscrito por la mayoría de los realizadores chilenos e instituciones como el Departamento de Cine Experimental de la Universidad de Chile y la Escuela de Artes de la Comunicación de la Universidad Católica (Mouesca y Orellana 1998: 302). Más aún, la producción cinematográfica -en especial el área documental- fue responsable de numerosas obras relativas al proceso político, el ideario de Salvador Allende y sus protagonistas sociales, cuyos testimonios fueron llevados a un primer plano como nunca antes en el cine nacional.

\section{A la sombra del sol}

A la sombra del sol es en muchos aspectos heredera de las tradiciones del arte durante el gobierno popular de Salvador Allende, un documento visual cuya doxa (ese campo de presupuestos que los partícipes de un proceso consideran como de suyo y que no admite discusión) era tan evidente que un entrevistador de Caiozzi, un crítico de cine de bastante experiencia, tuvo pocas dudas al preguntar si la película estaba relacionada con el "cine comprometido" (Silva 1974).

La película trata de un hecho de sangre en apariencia ocurrido a finales de los años 40. Dos delincuentes huyen desde la cárcel de Calama y se internan en el Desierto de Atacama en dirección a Bolivia. En su camino tropiezan con el pueblo cordillerano de Caspana, donde los habitantes les reciben de manera hospitalaria. Más tarde, los prófugos violan a dos pastoras y son detenidos por los miembros de la comunidad, quienes en el curso de un juicio comunal son condenados al fusilamiento. Aunque sabemos muy poco acerca de la exactitud de los hechos de esta historia, que los directores adjudican al entonces director del Teatro de Antofagasta Pedro de la Barra, lo cierto es que la película intenta recrear estos hechos de manera verosímil. Sin embargo, sabemos que no hubo una investigación histórica o antropológica, por consiguiente, muchos de los eventos debieron ser simplemente imaginados.

Uno de los efectos de realidad más poderosos en la película fue el uso de la población local como intérprete. Un recurso propio del neorrealismo italiano, que en asociación a una imagen de carácter inequívocamente documental-muchas de la secuencias del film lucen como documental y hay otras que simplemente lo son- permitieron hacer ingresar el relato al reino de la historia como acontecimiento real. Esto, sin embargo, no puede ser fuente de confusión, pues al fin y al cabo A la sombra del sol es una película de ficción, un producto colectivo de la experiencia e imaginario de sus guionistas y realizadores, que por definición transgrede el imaginario que deviene del relato oral o escrito, estabilizándolo materialmente a través de la fotografía y sus imágenes. Un film es un artefacto visual.

Para el analista, un film se torna legible en tanto se es capaz de apreciar más el modo de aparición de sus enunciados que el significado manifiesto de ellos (ver Stam et al. 1999: 91 y siguientes). Este ojo entrenado (y suspicaz) debe reconocer e identificar los procesos de selección de las unidades visuales, cuyas formas y contenidos coexisten de modo indisoluble en el significado, sentido que es siempre la objetivación del consciente e inconsciente cultural de sus creadores. Un proceso análogo opera en la selección de la temporalidad, pues se trata de relaciones que son imposición necesaria en el logro de una determinada linealidad. Sucesiones, yuxtaposiciones, embragues y estructuraciones constituyen órdenes, operaciones superiores de sentido que definen el lugar en el mundo del evento fílmico, que es uno o varios, pero no cualquiera. En esta clase de artefactos visuales, considerados más acá de su aspecto mercantil, su circulación o consumo, podemos reconocer procesos fenomenológicos, estructurales y dialécticos que son inherentes a toda práctica humana, singulares desde el punto de vista cultural, particulares desde el punto de vista de la historia.

\section{Imágenes utópicas}

En el comienzo del film, los fugitivos son emplazados en el desierto absoluto, haciendo manifiesta la pequeñez del sujeto ante sus imponentes extensiones y agresivas cualidades climáticas. Es un paisaje sobrecogedor y funesto. Los dos hombres no están preparados para las inclemencias del frío nocturno y el abrasador calor diurno. Con apenas un par de botellas de agua dulce, las posibilidades de supervivencia son pocas, más aún cuando el único curso de agua que hallan en su camino está contaminado por sales que hacen imposible su consumo. Abandonados a un destino incierto son entonces recompensados con un verdadero milagro, sin saber cómo tropiezan con un poblado agrícola, que en el contexto del relato aparece como un pequeño trozo de paraíso donde la vida ha vencido de manera inexplicable la esterilidad de un territorio donde en apariencia no hay vida. El poblado de la película, que no puede ser confundido con la comunidad real, está habitado 
por un grupo humano que se nos presenta como una reserva social. Viven en la prosperidad y todos son uno, casi no trabajan y disfrutan fiestas donde hay abundante comida y bebida. Este paraíso de paz y felicidad hace referencia al comunismo primitivo, una forma social que sabemos no ha existido nunca en la historia de la humanidad, pero que en el mundo intelectual de la izquierda de la época constituía una verdad del discurso, una realidad del imaginario social donde supuestamente no existía la lucha de clases y primaba la igualdad entre los miembros de una comunidad.

El escenario del film se desplaza, y junto a los protagonistas transitamos desde una naturaleza que clausura la vida social hacia un dominio cultural donde la vida social es plena. Es en este momento cuando podemos observar y asimilar la construcción de una rica y finamente estilizada caracterología social. La tipología es amplia y no exenta de matices, pero es especialmente inequívoca en relación a la pareja de delincuentes, los pobladores de la comunidad y el afuerino que oficia de mecánico y ha sido acogido en este grupo social. Todos los personajes aparecen bosquejados visualmente con la sencillez de los sujetos del mundo popular, sin embargo, sus conciencias de ser en este mundo de fantasía difieren de manera precisa: los prófugos son cínicos, disimulan o no asumen su maldad; el adoptado se sabe extranjero, pero en su autoexilio ha encontrado su lugar; los comuneros son el referente de la igualdad, generosidad y la felicidad. El lumpen y el paria aparecen retratados cabalmente, pero los pobladores lucen cierta ambigüedad. Sabemos por los diálogos y otras expresiones que se trata de indígenas, pero en términos estrictamente visuales existen escasas indicaciones de su identidad. Para quienes hemos trabajado en la región, es demasiado obvio el retiro o ausencia de esas marcas, que en lo real y ordinario son visiblemente identitarias en el campo de las prácticas andinas de lo ceremonial.

El tratamiento visual de lo indígena en el film, lejos de la exotización bastante común en este medio, evoca más a un campesino pobre que al nativo andino del film actual. Este aspecto es revelador, en especial si constatamos la presencia de un camarógrafo cuya mayor experiencia fílmica estaba en relación con los protagonistas privilegiados del proceso liderado por la Unidad Popular. El nombre de Jorge Müller aparece asociado en la realización de numerosos documentales, como Crónica del salitre (1971), La batalla de Chile (1973-1979) y numerosos noticiarios de Chile Films. En A la sombra del sol el nativo aparece campesinizado, una solución visual cuya afinidad con la época es mayor si consideramos el imaginario social que le corresponde y donde la categoría "pueblo" o "popular" era sinónimo exclusivo de trabajador, obrero o campesino. Durante ese período no existían los "pueblos originarios" y los indígenas eran simplemente campesinos.

Más allá de las inflexiones relativas al modelado de la imagen, está el relato y sus argumentos donde estas distintas categorías narrativas establecen una relación de organización y estructuración. La oposición delincuentes/comunidad cambia de estados, primero es diálogo sin interlocución y luego violación, ruptura, agresión. Ciertamente, la violación es física pero también es violación de la norma social. Al romper las reglas de convivencia ambos polos del relato entran en contradicción. Entonces el pueblo se organiza, aprisiona a los criminales y los juzga de manera comunal. La naturaleza social de la justicia es incuestionable, y en el film nos es indicada de manera abierta, clara y directa. Pero es en la secuencia de captura (algo que no está en el relato que dio origen a la película) donde se sitúa el hecho visual más revelador sobre este asunto. En esta, el hermano de una de las víctimas intenta hacer justicia por sus propias manos, pero es detenido y condenado moralmente por el grupo (Figura 1). El imaginario socialista de izquierda, tal vez el más ortodoxo, se instala aquí a cabalidad, pues en ese horizonte mítico de lo social, el individuo como ser individual no existe como tal, sólo es posible en la medida que es expresión de su sociedad.

En el desenlace del film, la comunidad y su modo de vida pacífico e igualitario quedan expuestos a una realidad impensada y es víctima de una segunda contradicción. No posee instrumentos para ejecutar la sentencia, pues como el cliché de prensa anunciaba, ellos no conocían la violencia. La estructura y oposición queda entonces sujeta a la mediación, al único vínculo posible de solución, que por definición es exterior. Aquí es donde el paria entra en "acción", él comparte la cultura de los criminales, pero también es "otro". El mecánico lleva por nombre Stephen, es de ascendencia extranjera, probablemente un producto de la inmigración, el puente perfecto entre estos dos mundos irreconciliables. La única arma de fuego en el poblado le pertenece y es precisamente el instrumento elegido para la ejecución. La solución es sin duda lógica, pues si el arma 

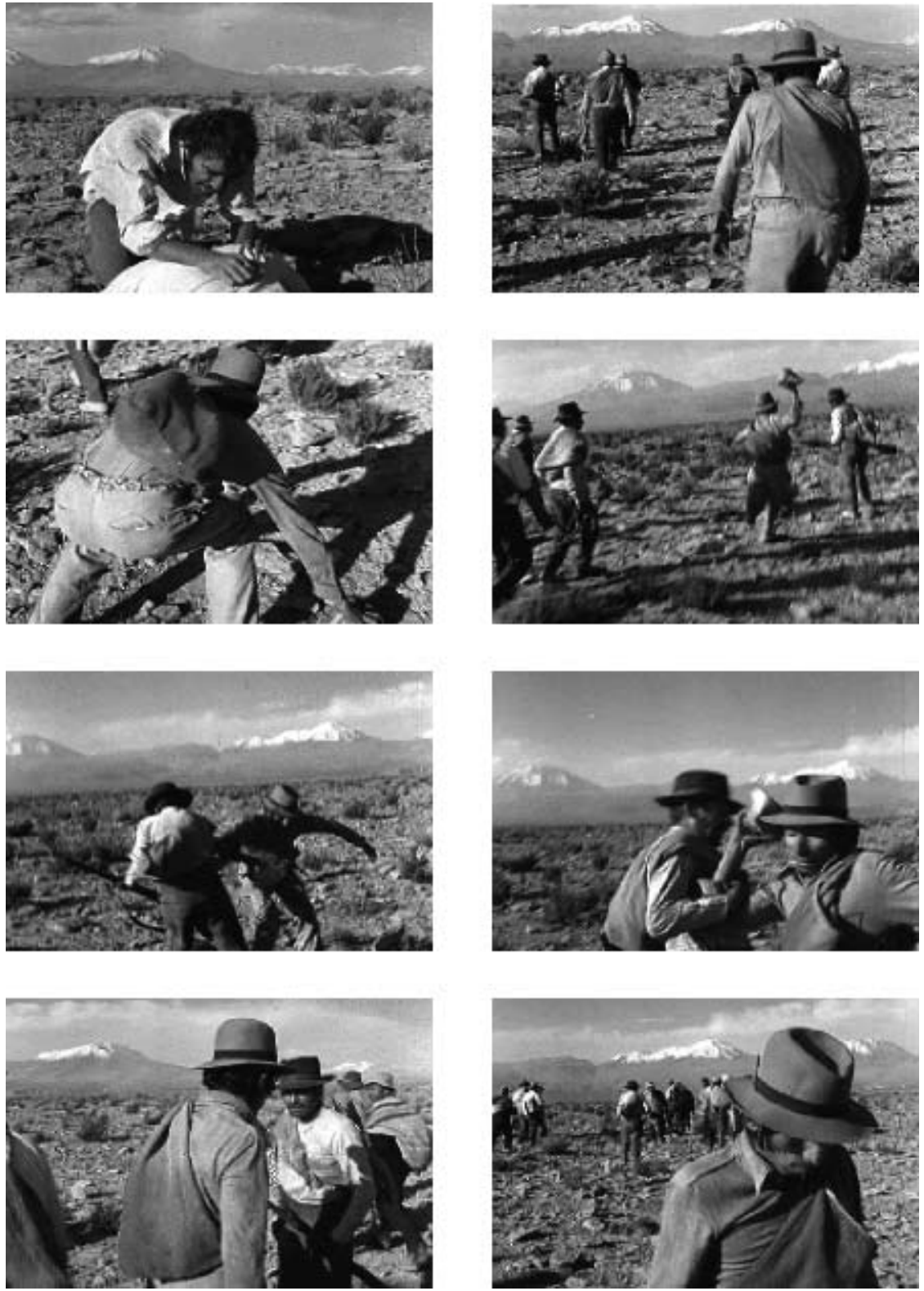

Figura 1. Escena que sanciona negativamente la justicia individual.

fuera propiedad de la comunidad, la caracterología utópica de lo social -signo clave de la construcción dramática- quedaría cancelada.

Todo guión cinematográfico debe respetar cierta racionalidad, pues en ella descansa lo verosímil del relato. Por esto es comprensible que el film vulnere su propia "ficcionalidad", integrando dentro y no fuera del relato los testimonios de aquellos caspaneños que podían acreditar lo ocurrido como acontecimiento real (Figura 2). Una decisión cuya lectura es necesariamente doble, pues en tanto el cine es un arte, su práctica no puede renunciar a la metáfora. Poética que para la época de inspiración socialista en Chile debía provenir de la realidad, categoría del pensamiento que era equivalente a la verdad. Se trataba de una utopía cuyo reverso era una ideología, pues la inclusión de los testimonios de los participantes no sólo eran la prueba de la verdad de lo ocurrido, sino que, al mismo tiempo, servían de validación inconsciente de la película y el contenido modelado arbitrariamente por sus 

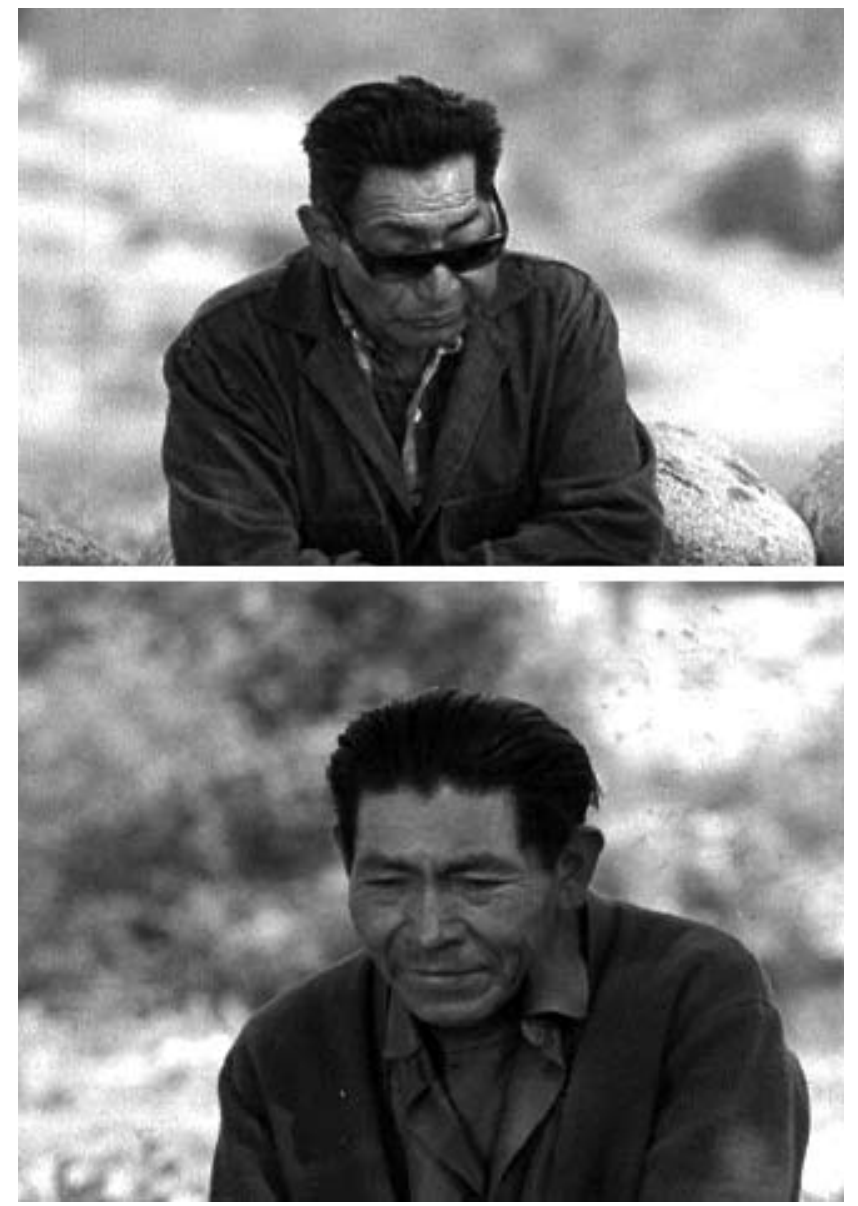

Figura 2. Comuneros de Caspana que conocían la historia que inspiró la película.

autores. Más que un error, este fue un acto de ingenuidad cultural que prevaleció durante el período de la Unidad Popular. ${ }^{4}$

\section{Epílogo}

El tema de la justicia popular y su relación con el efímero proyecto socialista chileno es evidente, fue proclama callejera y discurso encendido, una reivindicación de pancarta y mural. Pero es en $A$ la sombra del sol donde alcanza su más sofisticada expresión cultural. Una forma de justicia que al igual que el comunismo (el reino de la justicia y la libertad) sólo quedó en evidencia en el terreno puramente ficcional de la utopía, pero que como sabemos su reverso es siempre una ideología. Una

4 Sobre la relación entre ideología y utopía, ver Jameson (1989). representación equívoca respecto a las verdaderas relaciones sociales de producción del período, que al ser consideradas en vías de superación contribuyó a la ceguera de sus actores ante la catástrofe. Evolucionismo vehemente e ingenuo que afectó a todos quienes nos considerábamos militantes de esa ilusoria verdad.

El pensamiento de izquierda, el arte comprometido y el itinerario político de la Unidad Popular infiltraron con poca modestia A la sombra del sol, al punto de volverla una obra de carácter residual, anacrónica, en relación al contexto histórico de su realización y circulación. Sólo mucho tiempo después Caiozzi y Perelman han podido darse cuenta del uso de la justicia popular en su film y reparar en lo peligroso que fue ese acto inconsciente. Sin embargo, A la sombra del sol de ningún modo puede interpretarse como una parodia o una caricatura. Por el contrario, 
es la prueba tangible que las expectativas aludidas en el Manifiesto de cineastas chilenos habían cristalizado en un estilo propio, que lejos de ser una forma vulgar de realismo socialista, adscribía con propiedad aquello de que el cine es un arte y un instrumento de reflexión. Tal vez hoy esto importe poco, pero es hora de corregir la idea de que $A$ la sombra del sol fue la primera película en dictadura, porque en honor a la verdad histórica fue más bien la ultima obra de carácter socialista, un gesto artístico $\mathrm{y}$ visual que, como todo lo que ha sido, permanece en la penumbra de los tiempos de la Historia.

Agradecimientos A Pablo Perelman y Silvio Caiozzi, quienes generosamente me concedieron entrevistas para hablar de su película y el pasado.

\section{REFERENCIAS CITADAS}

BILBATUA, M., 1971. Teoría y lenguaje en el cine mudo soviético. En Cine soviético de vanguardia, pp. 7- 35. Alberto Corazón Ediciones, Madrid.

DEMETZ, P., 1968. Marx, Engels y los poetas. Editorial Fontanella, Barcelona

JAMESON, F., 1989. Documentos de cultura, documentos de barbarie. Visor distribuciones S.A., Madrid.

LENIN, W. I., 1976 [1905]. Sobre la literatura y el arte. Editorial Progreso, Moscú.

LUKACS, G., 1969 [1963]. Realismo: ¿Experiencia socialista o naturalismo burocrático? En Realismo: ¿Mito, doctrina o tendencia histórica?, pp. 7-35. Editorial Tiempo Contemporáneo, Buenos Aires.

MARX, C., 1970 [1859]. Introducción. En Fundamentos de la crítica de la economía política (esbozo de 1857-1858 en
Anexo 1850-1859), pp. 23-47. Editorial de Ciencias Sociales del Instituto del Libro, La Habana.

MOUESCA, J. y C. ORELLANA, 1998. Cine y memoria del siglo $X X$. LOM Ediciones, Santiago.

PLEJANOV, J., 1929 [1912]. El arte y la vida social. En El arte y la vida social, pp. 21-143. Editorial Cenit, Madrid.

SILVA, M., 1974. Imágenes a pleno sol. Ercilla, 4 de diciembre a 10 de diciembre, pp. 47-48, Santiago.

STAM, R., R. BURGOYNE y S. FLITTERMAN-LEWIS, 1999. Nuevos conceptos de la teoría del cine. Ediciones Paidós, Barcelona.

VEGA, A., 1980. Re-visión del cine chileno. Editorial Aconcagua, Santiago.

WILLIAMS, R., 1980. Marxismo y literatura. Ediciones Península, Barcelona. 